\title{
Manufacturing Enterprise Reverse Logistics
}

\author{
Lei Liu ${ }^{1}$ and Ting $\mathrm{Cai}^{2}$ \\ 1 Department of Electronic and Information Engineering, Jiangxi Industry Polytechnic College; \\ Jiangxi Nanchang; 330095 \\ 2 Department of Electronic and Information Engineering, Jiangxi Industry Polytechnic College,; \\ Jiangxi Nanchang; 330095
}

Keywords: Reverse Logistics; Manufacturing Enterprises; Operational Patterns of Reverse Logistics

\begin{abstract}
With the development of economy and technology, product replacement circle becomes rapid with a shorter life cycle, and manufacturing enterprises produce a glittering array of products, which will soon come to an end. Under the influence of environmental consciousness and legally binding force, the reverse logistics strategies have gradually become an important means for manufacturing enterprises to strengthen the competence. At the same time, suitable reverse logistics strategies not only help to ignite new profit sources, reduce manufacturing cost and increase customer satisfaction, but also help the management timely solve the problem and improve product quality. This paper analyzes how can manufacturing enterprises choose suitable reverse logistics strategies and compare with different operation modes in the premise of analyzing the current development condition of both domestic and foreign reverse logistics.
\end{abstract}

\section{Introduction}

With the development of economy and technology, product replacement circle becomes rapid with a shorter life cycle, and manufacturing enterprises produce a glittering array of products, which will soon come to an end. Under the influence of environmental consciousness and legally binding force, the reverse logistics strategies have gradually become an important means for manufacturing enterprises to strengthen the competence. Manufacturing enterprises can inform managers of the quality, service, and sales information based on reverse logistics so that managers can timely solve problems. A reasonable reverse logistics operation mode plays a decisive role in improving the performance of enterprises and reducing the production of poor quality products and improving product quality. What's more, the emergence and development of reverse logistics have strategic meanings to many manufacturing enterprises.

The Current Situation of Reverse Logistics at Home and Abroad

The current situation of reverse logistics abroad. In the reverse logistics system optimization research, foreign researchers mainly establish a dazzling array of optimization models based on linear programming. There is one common feature for this model, namely, to optimize the cost and efficiency of recycled products. In addition, it focuses on the products recycling in the premise of taking into account of the fixed cost, variable cost, distribution cost and sales income to cooperate with the government, so as to control the volume and properly arrange the recycling location and processing ability. As a result, it should achieve the optimal performance. With the gradual deepening of the study of reverse logistics, its strategic position has been highlighted.

The current situation of reverse logistics at home. Reverse logistics started late in China at a low development speed. In addition, people only have a shallow understanding toward the reverse logistics. In recent years, it has attracted more and more attention along with the economic development. Moreover, a dazzling array of researches changes their research direction from connotation, characteristic and the causes to optimal design. 


\section{Factors that Need to be Considered in Operating Reverse Logistics in Manufacturing Enterprises}

National policies. The production which has been used by consumers after being put into the market will cause toxic and harmful substances to the environment without proper treatment. Therefore, the government published the relevant provisions for concrete issues. While selecting reverse logistics operation, manufacturing enterprises have to consider relevant rules so as to better solve the product recycling problem and its disposal.

Economic factors. The amount of investment in the beginning of establishing reverse logistics: While choosing the operation mode, the amount of investment is the issue to be emphatically considered.

Available profits. If enterprises choose the self-operation model, the profit mainly refers to the value acquired in the second time by waste recycling, which can help enterprises to reduce the cost.

Investment cost. In the course of constructing reverse logistics, enterprises have to invest a lot of capitals if they chose self-operation mode or joint-management mode except for the beginning period. Therefore, the investment cost is a factor which inevitably needs to be considered while choosing operation model.

\section{Management Factors}

Management on facilities. If manufacturing companies aim to develop the reverse logistics, the smooth operation of management on facilities is a guarantee. Regardless of which mode of operation is selected, manufacturing companies have to carry out evaluation based on the real ability in order to select a suitable development mode.

Management on operating personnel. If manufacturing enterprises want to establish independent reverse logistics, they have to demand higher requirements on the working ability and operation ability so as to guarantee enterprises will train the employees and make a series of assessment systems to strengthen the management on operating personnel. In addition, if manufacturing enterprises want to choose joint-management reverse logistics operation mode, they have to discuss with other enterprises to conduct the personnel management so that they can possess certain operation ability as well as abilities to deal with the emergencies. Therefore, enterprises can accurately, independently, effectively and professionally run reverse logistics even when they cannot have a good knowled ge of the specific operation. In addition, if they choose to outsource the third party which is engaged in reverse logistics, they have to guarantee that they always have close connections with the third party and timely have a good knowledge of the condition of operating personnel and assist the third party to figure out proper training measures and evaluation mechanism.

Management on reverse logistics information. If manufacturing enterprises want to choose self-operation mode, they have to guarantee the effective flow of reverse logistics in logistics management, product design, manufacturing and management departments so as to prove ensure that the problems will be successfully dealt with. In contrast, the joint-management mode and the mode of sourcing to the third party pay more attention to the information communication among various enterprises so as to strengthen their understandings. The selection of reverse logistics operation mode asks manufacturing enterprises to possess the ability to manage information and solve information feedback.

Technical factors. Manufacturing enterprises do not only have to take into account the professional and technical features of equipments but also the technical abilities of operating personnel if they want to choose suitable reverse logistics cooperation model. That is to say enterprises have to know what abilities they possess to solve problems that might happen in the course of constructing reverse logistics so that to guarantee that the product value and environmental protection. 


\section{Existing Problems and Solutions for Manufacturing Enterprises Choosing Operation Models}

\section{Existing Problems}

\section{External Problems}

The general atmosphere of reverse logistics is not mature. In the market, there is not a common rule for various enterprises to choose reverse logistics operation model. What's more, there are successful cases. As a result, the pricing and management are arbitrary, which cannot form industry scale in terms of reverse logistics filed. Moreover, while choosing operation mode, there are not references.

The positions of manufactures and downstream retailers are different. From the retailers' point of view, if the damages are not caused by consumers, all products should be returned to its original state and ask for full compensation. However, manufacturers will certainly find many reasons to avoid compensation so as to ensure their own interests.

Unpredictable external factors. Establishing reverse logistics can help enterprises to reduce and avoid business risks for customers in the downstream supply chain. However, enterprises adopt loose recycling policies, the risks of enterprise are increased and the risks shift from the downstream to upstream. On the other hand, the information is exaggerated so it is not accurate.

\section{Internal problems}

The internal department of manufacturing enterprise does not pay enough attention to so the selection is arbitrary;

Manufacturing enterprises voluntarily give up reverse logistics development; The logistic for traditional enterprises is forward logistics and enterprises do not have to recycle those products which cannot be used. At present, not all enterprises pay attention to the reverse logistics management. Besides, for many middle and small scale enterprises, it is a pressure for them to establish reverse logistics and they want to focus on the construction and management of forward logistics.

There is shortage in terms of facilities, equipment, personnel, technology and manage ment. Regardless of which mode of operation is selected, the reverse logistics is not perfect, and facilities as well as personnel are not professional. In addition, the slackening management is a problem which cannot be avoided regardless of the selection.

Impe rfect supervision and management system of reverse logistics. In terms of product recycling, some problems worth be paid attention to: the recycling product circle is faster than the discarded circle, there is a glittering array of recycled products, the recycling period is long, and the overall recycling cost is unknown. In order to solve these problems, it is important to shorten the recycling circle.

\section{Practical Solution}

\section{Solutions for External Problems}

Manufacturing enterprises have to be initiative. With the development of economy, it is hard for relevant national departments to timely master the reverse logistics information. At this time, enterprises not only have to take into account of the relevant regulations but also win the support of sky rocketing consumers, so as to choose suitable reverse logistics. To conclude, enterprises have to take the initiative to choose the proper reverse logistics mode and make consumers know more about the condition.

Keep good communication and coope ration between downstream retailers. Concerning problems which may happen in the development course, manufacturing enterprises have to timely communicate with retailers and make relevant measures so as to guarantee its smooth implementation. In addition, researchers have to make retailers to know the operation mode of the reverse logistics and help retailers know that the development of reverse logistics is not always sweet.

Focus on the process. The unstable external factors increase the risks of manufacturing 
enterprises. Then, manufacturing enterprises have to select allay mode to establish the processing center of reverse logistics to focus on process or outsource to the third party to reduce the risk.

\section{Solutions for External Problems}

Strengthen the reverse logistics consciousness to know the importance of proper operation mode. Firstly, in the production process, manufacturing enterprises have to take into account of the material selection and consider whether it will increase the recycling difficulties or not; what's more, enterprises have to carry out professional training to help employees know proper reverse logistics, which is important to the development of enterprises.

Manufacturing enterprises have to comprehensively evaluate themselves so as to choose proper operation mode. Before enterprises are able to independently establish the reverse logistics, they can choose joint-management mode or outsource the business to the third party. However, enterprises have to take the initiative to participate in activities and pay attention to the reverse logistics management, trying remitting efforts to develop the reverse logistics to forward logistics, which cannot be ignored.

Purchasing professional facilities and strengthen personnel management and training. Manufacturing enterprises have to evaluate the professional ability of facilities while choosing any reverse logistics mode, so as to ensure effective and high quality implementation. Besides, professional skills of personnel should be improved so as to strengthen the management on personnel.

Establish reverse logistics information system to supervise and manage the reverse logistics. In order to ensure the smooth progress of reverse logistics, researchers have to establish a perfect reverse logistics information system to supervise and manage the reverse logistics. Reverse logistics involves more than one product, but recycling of several or dozens of product. While choosing operation mode, researchers have to make sure whether the reverse logistics information system is perfect or not, which is beneficial for enterprises to manage the recycling, reduce the mistakes in processing and improve the efficiency of reverse logistics operation.

\section{Conclusions}

In China, selections and researches on the reverse logistics and operation mode are still in the reference and exploring stage. Selection of proper reverse logistics mode not only helps to develop enterprises but also protects the environment and conserve resources. This paper starts from the basic concept to analyze its operation mode of self-management and joint-management, the connotation, features and application of sourcing operation mode. Besides, it also analyzes the differences of these three models from different perspectives. Along with the enhancement of environmental awareness and laws as well as regulations, manufacturing enterprises choosing reverse logistics operation will protect the environment, reduce the cost, and establish good social image yet with problems. This paper aims to come up with relevant solutions aimed at various questions and provide references to reverse logistics construction, which is also a problem to be considered in choosing the operation mode.

\section{References}

[1]Dong Rui, Discussion on How Enterprises Choose Reverse Logistics Operation Mode [J]. China Business \& Trade2013, (27):115-116.

[2]Wang Daqin, Zhang Lihua, Jiang Liang, Method Study on the Selection Approach for Manufacturing Enterprises Choosing Reverse Logistic Mode [J]. Shanghai Management Science2013, (3) : 85-88.

[3]Chen Yaping. Manufacturing Enterprises' Reverse Logistics Mode Selection [J]. Value 
Engineering, 2014, (01): 17-19.

[4]Dong Rui, Discussion on How Enterprises Choose Reverse Logistics Operation Mode [J]. China Business \& Trade2013, (27):115-116.

[5]Zong Gang, Zhao Hongtao. The Function and Problems Manufacturing Enterprises Have in the Course of Implementing Reverse Logistics [J]. Modern Markets, 2013, (25):111-111.

[6]Jiang Mingguang, Chen Liangyun. Analysis on Main Problems of Manufacturing Enterprises Implementing Reverse Logistics [J]. Pioneering with Science \& Technology Monthly, 2014, (01):70-71.

[7]Hu Wanjun. A Study on Networking Building of Manufacturing Enterprises Implementing Reverse Logistics [D].2014.

[8]Liu Feng. A Study on the Selection and Networking Building of Home Appliance Manufacturing Enterprises Implementing Reverse Logistics [D].2013. 